\title{
Improvement of the Adhesive Strength between Silicone-Based Soft Liner and Thermocycled Denture Base with Plasma Treatment
}

\author{
Xiaoqing $\mathbf{M}^{1,2}$, Chunyuan Qiao ${ }^{1,2}$, Xin Zhang ${ }^{1,2}$, Yingying Chen ${ }^{1,2}$ and Huaiqin Zhang ${ }^{1,2 *}$ \\ ${ }^{1}$ Jiangsu Key Laboratory of Oral Diseases, Nanjing Medical University, Nanjing 210029, People's Republic of China \\ ${ }^{2}$ Department of Prosthodontics, Affiliated Hospital of Stomatology, Nanjing Medical University, Nanjing 210029, People's Republic of China
}

\begin{abstract}
Purpose: The aim of this study was to investigate the effect of oxygen plasma treatment on the tensile bond strength of a silicone-based soft liner to a thermocycled denture base.

Methods: $210 \times 10 \times 1 \mathrm{~mm}$ heat-polymerized acrylic resin blocks for X-ray photoelectron spectroscopy (XPS) analysis were prepared (one served as control, and another treated by oxygen plasma for $4 \mathrm{~min}) .30(10 \times 10 \times 1 \mathrm{~mm})$ acrylic resin blocks for contact angle measurement and $80(8 \times 10 \times 30 \mathrm{~mm})$ for tensile test were also prepared and equally divided into five groups: a control group and four experimental groups (exposure to oxygen plasma for $1 \mathrm{~min}, 2 \mathrm{~min}, 3 \mathrm{~min}$ and $4 \mathrm{~min}$, respectively). All blocks were thermocycled $\left(5-55^{\circ} \mathrm{C}, 5000\right.$ cycles) before oxygen plasma treatment. After oxygen plasma treatment, the soft liner was processed between two blocks according to manufacturer's instructions and polymerized. All specimens were submitted to a tensile test using a universal testing machine and results were statistically analyzed (ANOVA, $p<0.05$, Tukey's HSD test).

Results: The XPS analysis showed that the O/C ratio increased from 0.324 for the control group to 0.498 for the 4-min exposure group. With regard to water contact angle, the lowest value was obtained from the 4-min exposure group $\left(37.32^{\circ}\right)$. For the tensile test, the highest tensile bond strength was observed in the 4-min exposure group (1.998 $\pm 0.110 \mathrm{MPa})$ and the lowest was in the control group $(0.831 \pm 0.059 \mathrm{MPa})$.
\end{abstract}

Conclusions: Oxygen plasma treatment was efficient in improving the tensile bond strength between siliconebased soft denture liner and thermocycled denture base.

Keywords: Oxygen plasma; Thermocycled denture base; Silicone soft liner; Adhesive strength

\section{Introduction}

The loss of natural teeth may result in psychosocial problems and inability for patients to perform functions. These problems can be corrected with the placement of removable dentures. However, some patients are not able to withstand the forces transmitted by denture bases because of sharp alveolar ridge, atrophied ridge, and thin atrophic mucosa. Resilient denture liners are used to cushion the inner surface of removable dentures, helping to evenly distribute mastication forces, preventing trauma of sensitive mucosa, enhancing denture retention by engaging undercuts $[1,2]$. The use of siliconebased resilient denture liner in mandibular complete dentures resulted in significant improvements in their satisfaction ratings compared with conventional heat-activated acrylic resin [3]. Soft lining materials can be divided into soft acrylic compounds and silicone elastomers. Soft acrylic compounds often contain plasticizers which may leach out of the compounds with time.

The silicones generally consist of a hydro- or vinyl-terminated polydimethylsiloxane (PDMS) and possess much higher structural elasticity [4,5]. However, some problems are associated with the use of resilient denture liners, including low tear strength, porosity, colonization by Candida albicans, and frequent bond failure between the liner and denture base during clinical use [2]. Debonding between the liner and denture base may create an environment for potential bacterial growth and accelerated breakdown of the soft liner [6,7]. Therefore, the lack of durable bond to the denture is major problem for the longevity of such prostheses. Mechanical surface preparation of denture base with lasers or alumina abrading had no significant effect on bond strength compared to untreated acrylic interfaces $[8,9]$. Plasma is a partially or wholly ionized gas that contains highly reactive particles including electronically excited electrons, ionic and free radical species, and photons in the short-wave ultraviolet (UV) range [10]. Plasma treatment is a gentle method to change the characteristics of the topmost layer of polymers. Plasma irradiation does not cause environmental pollution and is a useful method to increase adhesive strength between heat-cured acrylic resin and self-curing acrylic resin [11]. Recent study indicated that plasma treatment appeared to increase the tensile-shear bond strength between post and composite [12]. The bond strength between silicone-based soft liner and fresh denture base has been investigated in previous studies $[13,14]$. However, there is no paper that discussed the adhesion between silicone-based soft liner and aged denture base, although the aged denture base is frequently used in clinical practice. In the present study, thermocycling $\left(5-55^{\circ} \mathrm{C}\right)$ was used to simulate the aging process.

The objective of this study was to evaluate the plasma treatment effect on the tensile bond strength between silicone-based soft liner and thermocycled denture base. The null hypothesis of the study was that the plasma treatment would improve the tensile bond strength between silicone-based soft liner and thermocycled denture base.

*Corresponding author: Huaiqin Zhang, Department of Prosthodontics, Affiliated Hospital of Stomatology, Nanjing Medical University, Nanjing 210029, People's Republic of China, Tel: +86 85031831; E-mail: dentzhanghuaiqin@163.com

Received November 25, 2015; Accepted December 17, 2015; Published December 24, 2015

Citation: Xiaoqing M, Qiao C, Zhang X, Chen Y, Zhang H (2015) Improvement of the Adhesive Strength between Silicone-Based Soft Liner and Thermocycled Denture Base with Plasma Treatment. Dentistry 5: 351. doi:10.4172/21611122.1000351

Copyright: (c) 2015 Xiaoqing M, et al. This is an open-access article distributed under the terms of the Creative Commons Attribution License, which permits unrestricted use, distribution, and reproduction in any medium, provided the original author and source are credited. 


\section{Materials and Methods}

\section{Materials}

The soft denture liner used was a silicone-based material and the denture base material was a heat-cured poly (methyl methacrylate) (PMMA) acrylic resin. Their types, batch numbers and manufacturers are presented in Table 1.

\section{Preparation of specimens}

2 blocks $(10 \times 10 \times 1 \mathrm{~mm})$ for X-ray photoelectron spectroscopy (XPS) analysis (one served as control, and another treated by oxygen plasma for $4 \mathrm{~min})$ and 30 blocks $(10 \times 10 \times 1 \mathrm{~mm})$ for water contact angle measurement were prepared. Blocks for water contact angle measurement were divided into five groups $(n=6)$ according to the different exposure time applied ( $1 \mathrm{~min}, 2 \mathrm{~min}, 3 \mathrm{~min}$ and $4 \mathrm{~min}$, respectively).

In order to prepare the resin blocks for tensile test, a mold was made by investing 2 brass dies of $8 \times 10 \mathrm{~mm}^{2}$ cross-sectional area and $30 \mathrm{~mm}$ length, together with a spacer ( $3 \mathrm{~mm}$ thick), in hard but flexible silicone rubber (Addition silicone duplicating material) [15]. Molten wax was poured in the mold and allowed to cool, harden and subsequently to be invested in dental stone in a dental flask. After the dewaxing procedures, the heat-cured acrylic denture base resin were packed in the mold and polymerized according to the manufacturer's instructions. After polymerization, the rectangular acrylic resin blocks were removed from the mold and the bonding surfaces were smoothed using 240grit aluminum oxide paper, cleaned, and dried. In this manner, a total of 80 resin blocks were prepared. Then all the resin blocks underwent 5,000 cycles in distilled water between $5^{\circ} \mathrm{C}$ and $55^{\circ} \mathrm{C}$, with a dwell time of 30 seconds in each bath [16]. Thus, 80 thermocycled resin blocks were obtained and equally divided into five groups: a control group and four experimental groups (exposure to oxygen plasma for $1 \mathrm{~min}$, $2 \mathrm{~min}, 3 \mathrm{~min}$ and $4 \mathrm{~min}$, respectively). Prior to application of the soft liner, the bonding surfaces of the acrylic resin blocks were treated with oxygen plasma for $1 \mathrm{~min}, 2 \mathrm{~min}, 3 \mathrm{~min}$, and $4 \mathrm{~min}$, respectively, and the control group received no surface treatment. A hypo-atmospheric pressure glow discharge (HAPGD) plasma treatment system (HPD2400, Nanjing Suman Electronics Co., Ltd, China) was used to modify the acrylic resin surfaces.

The operational parameters used in this study were: 20 mbar of the chamber pressure, $80 \mathrm{~W}$ of power, and the exposure time were fixed at $1 \mathrm{~min}, 2 \mathrm{~min}, 3 \mathrm{~min}$ and $4 \mathrm{~min}$, respectively. After plasma treatment, adhesive primer (Sofreliner Tough ${ }^{\circ}$ Primer) was applied to the bonding surfaces of the acrylic resin blocks according to the manufacturer's instructions. Then, the two acrylic resin blocks were secured back into the silicone mold, and the soft liner was applied to the space created before $(8 \times 10 \times 3 \mathrm{~mm})$ and polymerized following the manufacturer's instructions. After polymerization, the specimen was removed from the mold and trimmed with a sharp blade. In this manner, 40 rectangular specimens were obtained in a sandwich configuration with a centrally located PMMA portion for silicone-based soft liner (Figure 1).

\section{X-ray photoelectron spectroscopy (XPS) analysis}

The composition of elements on the surfaces of untreated and $4 \mathrm{~min}$ plasma treated resin blocks was investigated by an X-ray photoelectron spectrometer (XPS) (ESCALAB MK-II, VG Scientific Ltd., UK). An Mg $\mathrm{Ka}$ radiation was used as an $\mathrm{X}$-ray anode and the pressure inside the main chamber was lower than $5 \times 109 \mathrm{~mm} \mathrm{Hg}$.

\section{Water contact angle measurement}

Water contact angles of untreated and plasma-treated resin specimens were measured in air with a contact angle goniometer (SL200B, Solon Tech. Co., China). Deionized water (DI) was used as test fluid for all measurements, and was dropped onto the resin surface using a $1 \mathrm{ml}$ syringe. Each measurement was repeated three times and the average was considered as the final contact angle. The results were statistically analyzed using non-parametric analysis $(\mathrm{a}=0.05)$ by SPSS version 20.0 (SPSS Inc., Chicago, IL, USA).

\section{Tensile bond strength test}

At 48 hour water storage at $37^{\circ} \mathrm{C}$, all specimens were subjected to a tensile force at a crosshead speed of $10 \mathrm{~mm} / \mathrm{min}$ until failure in a universal testing machine (Serise IX, Instron corp, America). For each specimen, the maximum tensile force before failure was recorded. The tensile bond strength values were calculated as the force at debonding divided by the cross-sectional area of the interface. Data analysis was performed by using SPSS software (SPSS version 20.0 software, SPSS Inc., Chicago, IL, USA). Mean tensile bond strength values were compared by one-way ANOVA and multiple comparisons were carried out with the Tukey's HSD test. A p $<0.05$ was considered to be statistically significant.

\section{Results}

\section{XPS analysis}

Significant change occurred in the 4 min exposure group when compared with the control group. The $\mathrm{O} / \mathrm{C}$ atomic ratio increased from 0.324 for the control group to 0.498 for the 4-min exposure group. The curve-fitted high resolution C1s XPS spectra of the resin surfaces are shown in Figure 2. The high-resolution $\mathrm{C} 1$ s spectrum can be deconvoluted into three main chemical states, as $\mathrm{C}-\mathrm{H}, \mathrm{C}-\mathrm{O}$, and $\mathrm{O}=\mathrm{C}-\mathrm{O}$. The significant change occurred in the 4 min exposure group when compared with the control group was that the $\mathrm{C}-\mathrm{O}$ and $\mathrm{O}=\mathrm{C}-\mathrm{O}$ contents increased greatly.

\section{Water contact angle measurement}

The water contact angles of untreated and plasma-treated resin specimens are shown in Table 2 . There is a significant difference between control and each of the plasma treated groups $(\mathrm{p}<0.05)$. With oxygen plasma treatment, the water contact angle values dropped dramatically. Prior to plasma treatment, the acrylic resin blocks have average contact angle of $59.99^{\circ}$ and dropped to $37.32^{\circ}$ after 4 min exposure.

\begin{tabular}{|c|c|c|c|}
\hline Material & Type & Batch No. & Manufacturer \\
\hline Sofreliner Tough & $\begin{array}{c}\text { Addition-cured } \\
\text { Silicone }\end{array}$ & $\begin{array}{c}\text { N385246 } \\
\text { E38 (primer) }\end{array}$ & Tokuyama, Japan \\
\hline Zi Ran & Heat-cured PMMA & $\begin{array}{c}\text { FMIBG (powder) } \\
\text { FMIA (liquid) }\end{array}$ & Nissin, Kunshan, China \\
\hline
\end{tabular}

Table 1: Materials used in the study.

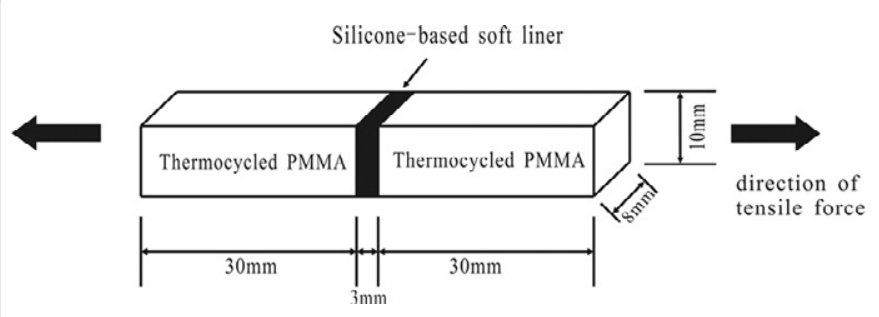

Figure 1: Schematic illustration of a specimen for tensile test. 

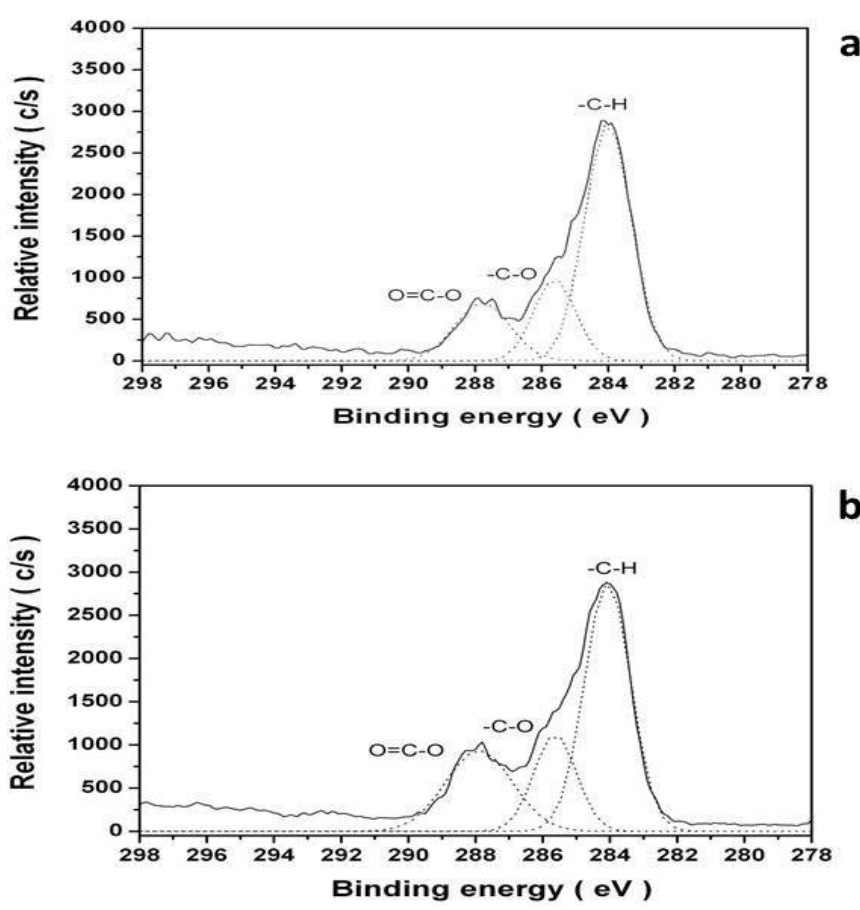

Figure 2: Curve-fitted high resolution C1s XPS spectra of acrylic resin surfaces: (a) control group; (b) 4-min exposure group.

\begin{tabular}{|c|c|}
\hline Group & Mean \pm SD \\
\hline Control & $59.99 \pm 10.00$ \\
1-min exposure & $44.44 \pm 3.08^{\mathrm{b}}$ \\
2-min exposure & $37.69 \pm 4.21^{\mathrm{b}}$ \\
3-min exposure & $42.69 \pm 3.79^{\mathrm{b}}$ \\
4-min exposure & $37.32 \pm 5.31^{\mathrm{b}}$ \\
\hline
\end{tabular}

SD: Standard deviation

Same superscripted letters indicate no significant difference $(p>0.05)$

Table 2: Water contact angle (in degrees) after plasma treatment $(n=6)$.

\section{Tensile bond strength test}

The mean tensile bond strength values and standard deviations of the groups are listed in Table 3. The results of the one-way ANOVA revealed that the bond strength values differed significantly between the control and each of the plasma treated groups $(\mathrm{p}<0.05)$. The highest bond strength value was observed for the 4 min exposure group $(1.998$ $\pm 0.110 \mathrm{MPa})$ and the lowest was observed for the control group $(0.831$ $\pm 0.059 \mathrm{MPa})$.

\section{Discussion}

Failure of the bond between the acrylic denture base resin and silicone-based soft liner is commonly encountered in clinical practice $[17,18]$. Frequent clinical evaluations and periodic replacement of soft liners are required $[2,19]$. During mastication, the oral cavity gets in contact with food at different temperatures. The temperature changes may affect the physical and chemical properties of the denture base, and affect the bond strength between the soft liner and the denture base [20]. The water sorption and solubility of the denture base would decrease the mechanical properties such as hardness, transverse strength, and fatigue limit, which would also affect the bond strength of soft liner and denture base [21]. In the present study, in vitro accelerated aging reproduced with thermocycling $\left(5-55^{\circ} \mathrm{C}\right)$ is used to simulate the oral condition. Temperatures of $5^{\circ} \mathrm{C}$ and $55^{\circ} \mathrm{C}$ were chosen since they are similar to the temperature of food and drink ingested and are well tolerated by the oral mucosa without causing any damage to it [22]. Pinto et al. reported that a single thermal cycle was assumed per meal and 5,000 thermal cycles would relate to roughly 5 years of use [18]. Old denture surfaces usually present problems in bonding and finishing due to their low hydrophilicity and low surface energy.

In this study, to increase the bond strength between the soft denture liner and the thermocycled denture base, a surface treatment modality, namely oxygen plasma treatment, was applied to the resin surface. The hypothesis of this study was that the bonding could be increased by the application of oxygen plasma treatment and the results of the study completely support this hypothesis. Through plasma treatment, oxygen-containing polar groups of $\mathrm{C}-\mathrm{O}$ and $\mathrm{O}=\mathrm{C}-\mathrm{O}$ were effectively introduced onto the thermocycled resin surface due to the highly reactive property of oxygen plasma [23,24]. This was in line with the conclusion drawn by Bicer et al. who demonstrated that polar functional groups were introduced onto the fresh resin surface after plasma treatment [25]. The value of oxygen-containing groups in the present study was higher than that in previous studies $[26,27]$. The reason was that the applied hypo-atmospheric pressure glow discharge (HAPGD) system provides more stable and homogeneous discharge with higher electron density when compared with the low pressure glow discharge system.

The presence of oxygen-containing groups improved the surface hydrophilicity of the plasma-treated resin surface as shown by the decrease in water contact angle [23]. It has been concluded that the smaller the contact angle, the greater the hydrophilicity [28]. Süzer et al. measured the water contact angle on plasma-treated resin surface and yielded values ranging between $48^{\circ}$ and $54^{\circ}$, which were significantly lower than those of untreated resins with an average value of $63^{\circ}$ [29]. In the present study, a lower value ranging between $37^{\circ}$ and $44^{\circ}$ was observed which indicated that a higher hydrophilicity was obtained compared with the control group. The improved surface hydrophilicity enhanced the penetration of the silicone-based soft liner into the irregularities on the resin surface and contributed to the increase in the tensile bond strength [23].

Silicone-based soft liners tested in the present study had a satisfactory bond strength to thermocycled denture base resin, which is significantly higher than the values observed in other studies [15,30]. Apart from the chemical oxidation reaction, oxygen plasma also has roughening effect on polymer surface. Masood et al. reported that plasma treatment increased the effective surface area of the resin and leads to a more intimate contact between the plasma-treated resin surface and the applied soft liner [31]. During plasma treatment, two competitive effects, namely oxidation effect and etching effect, take place. For the oxidation effect, the surface of the specimens was functionalized and the tensile bond strength of the specimens was increased. This was attributed to continuous introduction of oxygencontaining groups on the resin surface. For the etching effect, chemical

\begin{tabular}{|c|c|}
\hline Group & Mean \pm SD \\
\hline Control & $0.831 \pm 0.059$ \\
1-min exposure & $1.289 \pm 0.090^{\mathrm{b}}$ \\
2-min exposure & $1.436 \pm 0.107^{\mathrm{b}}$ \\
3-min exposure & $1.981 \pm 0.099^{\mathrm{c}}$ \\
4-min exposure & $1.998 \pm 0.110^{\mathrm{c}}$ \\
\hline
\end{tabular}

SD: Standard deviation

Same superscripted letters indicate no significant difference ( $p>0.05$, Tukey's HSD test)

Table 3: Tensile bond strength (MPa) of silicone-based soft liner to thermocycled PMMA ( $n=8)$. 
etching was promoted by free radicals generated in $\mathrm{O}_{2}$ discharge and physical etching occurred under strong ion bombardment [32]. Bicer et al. reported that, as the treatment time is extended, the etching effect dominates, causing the degradation of the polymer surface and decreasing the tensile bond strength [25]. Apart from the outer chain scissions, long time plasma treatment would also cause the inner chain scissions and affect the bulk properties of the denture [25]. Therefore, the duration of the plasma treatment is of importance. To sum up, by the results obtained the hypothesis could be completely accepted, because modifying the thermocycled resin surface by oxygen plasma treatment significantly increased the tensile bond strength of PMMA/silicone specimens. However, although in vitro accelerated aging reproduced with thermocycling was an accepted method for simulating the oral condition, the test conditions may not exactly simulate the clinical situations. Therefore, the clinical suitability of these results should be tested further by in vivo studies.

\section{Conclusions}

Within the limitations of this study, the following conclusions can be drawn. The XPS results showed that the O/C ratio increased dramatically and oxygen-containing groups of $\mathrm{C}-\mathrm{O}$ and $\mathrm{O}=\mathrm{C}-\mathrm{O}$ were introduced on the thermocycled resin surface after plasma treatment. The water contact angles of the plasma treated groups were lower when compared with the control group, which indicated that the hydrophilicity of the resin surface was significantly increased. The oxygen plasma treatment was efficient in improving the tensile bond strength between silicone-based soft liner and thermocycled denture base. The highest bond strength was observed for the 4 min exposure group.

\section{Acknowledgments}

The authors would like to thank the financial support from the Project Funded by the Priority Academic Program Development of Jiangsu Higher Education Institutions (2014-37).

\section{References}

1. Hatamleh MM, Maryan CJ, Silikas N, Watts DC (2010) Effect of net fiber reinforcement surface treatment on soft denture liner retention and longevity. $J$ Prosthodont 19: 258-262.

2. Krunic N, Kostic M, Petrovic M, Iqic M (2015) Oral health-related quality of life of edentulous patients after complete dentures relining. Vojnosanit Pregl 72: 307-311.

3. Kimoto S, So K, Yamamoto S, Ohno Y, Shinomiya M, et al. (2006) Randomized controlled clinical trial for verifying the effect of silicone-based resilient denture liner on the masticatory function of complete denture wearers. Int J Prosthodont 19: $593-600$.

4. Demir H, Dogan A, Dogan OM, Keskin S, Bolayir G, et al. (2011) Peel bond strength of two silicone soft liners to a heat-cured denture base resin. J Adhes Dent 13: 579-584.

5. Dogan OM, Keskin S, Dogan A, Ataman H, Usanmaz A (2007) Structureproperty relation of a soft liner material used in denture applications. Dent Mater J 26: 329-334.

6. Atsü S, Keskin Y (2013) Effect of silica coating and silane surface treatment on the bond strength of soft denture liner to denture base material. J Appl Oral Sci 21: 300-306.

7. Kulkarni RS, Parkhedkar R (2011) The effect of denture base surface pretreatments on bond strengths of two long term resilient liners. J Adv Prosthodont 3: 16-19.

8. Gundogdu M, Yesil Duymus Z, Alkurt M (2014) Effect of surface treatments on the bond strength of soft denture lining materials to an acrylic resin denture base. J Prosthet Dent 112: 964-971.

9. Gorler O, Dogan DO, Ulgey M, Goze A, Hubbezoğlu I, et al. (2015) The Effects of Er:YAG, Nd:YAG, and Ho:YAG Laser Surface Treatments to Acrylic Resin
Denture Bases on the Tensile Bond Strength of Silicone-Based Resilient Liners. Photomed Laser Surg 33: 409-414.

10. Gray JE, Norton PR, Griffiths K (2003) Surface modification of a biomedical poly(ether)urethane by a remote air plasma. Appl Surf Sci 217: 210-222.

11. Nishigawa G, Maruo Y, Oka M, Oki K, Minagi S, et al. (2003) Plasma treatment increased shear bond strength between heat cured acrylic resin and self-curing acrylic resin. J Oral Rehabil 30: 1081-1084.

12. Yavirach $P$, Chaijareenont $P$, Boonyawan $D$, Pattamapun $K$, Tunma $S$, et al (2009) Effects of plasma treatment on the shear bond strength between fiberreinforced composite posts and resin composite for core build-up. Dent Mater J 28: 686-692.

13. Akin H, Tugut F, Mutaf B, Akin G, Ozdemir AK (2011) Effect of different surface treatments on tensile bond strength of silicone-based soft denture liner. Lasers Med Sci 26: 783-788.

14. Kulak-Ozkan Y, Sertgoz A, Gedik H (2003) Effect of thermocycling on tensile bond strength of six silicone-based, resilient denture liners. J Prosthet Dent 89: 303-310.

15. Surapaneni H, Ariga P, Haribabu R, Ravi Shankar Y, Kumar VH, et al. (2013) Comparative Evaluation of Tensile Bond Strength between Silicon Soft Liners and Processed Denture Base Resin Conditioned by Three Modes of Surface Treatment: An Invitro Study. J Indian Prosthodont Soc 13: 274-280.

16. Soygun K, Bolayir G, Dogan A, Demir H., Dogan OM, et al. (2011) The Effect of Surface Treatments on Tensile Bond Strength between a Silicone Soft Liner and a Heat-Cured Denture Base Resin. J Adhesion 87: 951-965.

17. Mutluay MM, Ruyter IE (2007) Evaluation of bond strength of soft relining materials to denture base polymers. Dent Mater 23: 1373-1381.

18. Pinto JR, Mesquita MF, Nobilo MA, Henriques GE (2004) Evaluation of varying amounts of thermal cycling on bond strength and permanent deformation of two resilient denture liners. J Prosthet Dent 92: 288-293.

19. Pinto JR, Mesquita MF, Henriques GE, de Arruda Nobilo MA (2002) Effect of thermocycling on bond strength and elasticity of 4 long-term soft denture liners. J Prosthet Dent 88: 516-521.

20. Elias CN, Henriques FQ (2007) Effect of thermocycling on the tensile and shear bond strengths of three soft liners to a denture base resin. J Appl Oral Sci 15 18-23.

21. Mese A, Guzel KG, Uysal E (2005) Effect of storage duration on tensile bond strength of acrylic or silicone-based denture liners to processed denture base polymer. Acta Odontol Scand 63: 31-35.

22. Madan N, Datta K (2012) Evaluation of tensile bond strength of heat cure and autopolymerizing silicone-based resilient denture liners before and after thermocycling. Indian J Dent Res 23: 64-68.

23. Zhang H, Fang J, Hu Z, Ma J, Han Y, et al. (2010) Effect of oxygen plasma treatment on the bonding of a soft liner to an acrylic resin denture material. Dent Mater J 29: 398-402.

24. Nathawat R, Kumar A, Acharya NK, Vijay YK (2009) XPS and AFM surface study of PMMA irradiated by electron beam. Surf Coat Technol 203: 2600 2604.

25. Bicer AZY, Dogan A, Keskin S, Dogan OM (2013) Effect of Argon Plasma Pretreatment on Tensile Bond Strength of a Silicone Soft Liner to Denture Base Polymers. J Adhesion 89: 594-610.

26. Kaczmarek H, Chaberska H (2009) AFM and XPS study of UV-irradiated poly(methyl methacrylate) films on glass and aluminum support. Appl Surf Sci 255: $6729-6735$.

27. Wan Y, Qu X, Lu J, Zhu C, Wan L, et al. (2004) Characterization of surface property of poly(lactide-co-glycolide) after oxygen plasma treatment Biomaterials. 25: 4777-4783.

28. Ozden N, Akaltan F, Suzer S, Akovali G (1999) Time-related wettability characteristic of acrylic resin surfaces treated by glow discharge. J Prosthet Dent 82: 680-684.

29. Suzer S, Ozden N, Akaltan F, Akovali G (1997) Characterization of Denture Acrylic Resin Surfaces Modified by Glow Discharges. Appl Spectrosc 51: 17411744.

30. Wieckiewicz W, Kasperski J, Wieckiewicz M, Miernik M, Krol W (2014) The adhesion of modern soft relining materials to acrylic dentures. Adv Clin Exp Med 23: 621-625. 
Citation: Xiaoqing M, Qiao C, Zhang X, Chen Y, Zhang H (2015) Improvement of the Adhesive Strength between Silicone-Based Soft Liner and Thermocycled Denture Base with Plasma Treatment. Dentistry 5: 351. doi:10.4172/2161-1122.1000351

Page 5 of 5

31. Masood SH, Mohamed SA (2012) The effect of plasma treatment on the bonding of soft denture liners to heat cured acrylic resin denture base material and on some surface properties of acrylic resin polymer. J Bagh Coll Dentistry 24: 29-35.
32. Hegemann D, Brunner H, Oehr C (2003) Plasma treatment of polymers for surface and adhesion improvement. Nucl Instr Meth Phys Res B 208: 281-286. 